\title{
Amadeus
}

International Multidisciplinary Journal IISSN 2525-3281

DOI: 10.14295/aimj.v4i7.85

\section{Refugee Access to Higher Education in the World: A Systematic Review}

Elzenir Pereira de Oliveira Almeida

Arthur Oliveira Silva Myllena Maria de Morais Pereira,

Elysyana Barros Moreira ${ }^{2}$

Sâmia Israele Braz do Nascimento $^{3}$;

Sâneq Alaf de Freitas Oliveira ${ }^{4}$.

Vivianne Coelho Noronha Diógenes ${ }^{4}$.

Modesto Leite Rolim Neto ${ }^{2}$

\begin{abstract}
The aim of the article was to analyze educational policies for higher education in refugee populations worldwide. Methods: Systematic review using the PRISMA protocol. The study period was from September 2015 to December 2017; and the keywords included "Refugees," "Education," and "University", combined with the Boolean operator "AND." The statistic. For primary selection was the analysis of titles and abstracts, followed by eligibility based on inclusion criteria previously established. Results: The 29 articles included in this review originate from the online newspapers G1, Estado de São Paulo, Estadão, The Washington Post, The Independent, The Guardian and USA Today. In relation to the subject addressed. Conclusion: In response to the refugee crisis several groups are mobilizing. There are a huge amount of institutions directly addressing the most difficult challenges of society, the university is a chance to start over in the long run. We need investment in scholarships and programs to get refugees from high school to university. It is the responsibility of global educators to make this commitment currently.
\end{abstract}

Keywords: Refugee; Education; University

\footnotetext{
${ }^{1}$ University Center of Patos - UNIFIP and Federal University of Campina Grande - UFCG - Patos, Paraiba, Brazil.

${ }^{2}$ School of Medicine, Federal University of Cariri (UFCA), Barbalha, Ceará, Brazil. modestorolim@ yahoo.com.br;

${ }^{3}$ Estacio of Juazeiro do Norte Medical School (FMJ), Juazeiro do Norte, Ceará, Brazil.

${ }^{4}$ Regional University of Cariri (URCA), Crato, Ceará, Brazil.

* Autores correspondentes: elzeniroliver@gmail.com (Elzenir); modestorolim@yahoo.com.br (Modesto).
} 


\section{O acesso dos refugiados ao Ensino Superior no Mundo: Uma Revisão Sistemática}

\begin{abstract}
Resumo: O objetivo foi analisar as políticas educacionais voltadas ao ensino superior nas populações de refugiados a nível mundial. Métodos: Revisão sistemática, usando o protocolo PRISMA. O período de estudo foi de setembro de 2015 a dezembro de 2017; e as palavras-chave incluíram "Refugiados", "Educação" e "Universidade", combinados com o operador booleano "AND". A estatística. Para a seleção primária ocorreu pela análise dos títulos e resumos, seguida da elegibilidade baseada nos critérios de inclusão previamente estabelecidos. Resultados: Os 29 artigos incluídos nesta revisão são originários dos Jornais online G1, Estado de São Paulo, Estadão, The Washington Post, The Independent, The Guardian e USA Today. O estudo revelou que os refugiados possuem 36 vezes menos chance de ingressar no ensino superior do que alguém que não está em situação de refúgio. No entanto foi percebido uma quantidade de instituições que estão apoiando o acesso a universidade dos refugiados. Conclusão: Em resposta a crise dos refugiados diversos grupos estão se mobilizando. Há uma enorme quantidade de instituições abordando diretamente os desafios mais difíceis da sociedade, a universidade é uma chance de recomeço a longo prazo. Precisa-se de investimento em bolsas de estudo e programas para obter os refugiados do ensino médio para a universidade. É responsabilidade dos educadores globais assumirem esse compromisso neste momento.
\end{abstract}

Palavras-chave: Refugiados; Educação; Universidade.

\section{Introdução}

Grandes movimentos migratórios e crises de refugiados são constantes na história da humanidade. A linha divisória entre "migrantes" e "refugiados" deixou de existir na prática (Oliveira; Peixoto; Góis, 2017). Refugiados são pessoas que estão fora do seu país de origem devido ao medo da perseguição, do conflito, da violência ou de outras circunstâncias que perturbam seriamente a ordem pública. Este status internacionalmente reconhecido lhes garante acesso à assistência dos Estados, da ACNUR e das organizações relevantes (ACNUR, 2016a). "Migrante" é qualquer pessoa que vai a outro país para buscar trabalho, refúgio ou escapar de conflitos armados.

O artigo 14 da Declaração Universal dos Direitos Humanos estabelece o direito de cada pessoa procurar o asilo e as disposições da Convenção de 1951, que determinam todas as medidas de proteção e tratamento dos refugiados e tem como disposição mais 
importante, o princípio da não devolução, artigo 33. Os signatários do tratado de 1951 tem o dever de dar aos refugiados outros direitos básicos como o acesso à educação, o que pode ser caro. Para dificultar ainda mais a entrada em seus países, a maioria dos estados ocidentais limitam a concessão do status de refugiado aos candidatos que podem provar que tem medo de perseguição, o que é difícil, especialmente para os que não tiveram tempo para recuperar documentos de identidade (ACNUR, 2016b).

Apesar de ser difícil provar o status de refugiado, a ACNUR Classificou 13,6 milhões de pessoas no mundo como refugiados a partir de 2014. Em setembro de 2017, solicitou urgentemente 40 mil lugares de reassentamento para refugiados em 15 países prioritários para asilo e trânsito ao longo da rota do Mediterrâneo Central. Em contrapartida, recebeu cerca de 13.000 ofertas de reassentamento até o momento para 2018 e 2019, a maioria dos quais faz parte dos programas regulares de reassentamento estabelecidos globalmente (ACNUR,2018). Estima-se que quase 136 milhões de pessoas em todo o mundo dependerão de ajuda humanitária em 2018, $5 \%$ maior do que em 2017, a causa principal são os conflitos prolongados e atingem países como Iêmen (22,2 milhões em necessidade de ajuda emergencial), Nigéria (14,5 milhões), Síria (13,1 milhões), Iraque (8,7 milhões), Sudão do Sul (7 milhões) e Somália (6,2 milhões) (Antunes; Romero, 2018).

O Brasil contava com 8.863 mil refugiados de 79 nacionalidades em 2016, segundo dados do Comitê Nacional para Refugiados (CONARE). O maior número de reconhecimentos envolve sírios, angolanos, colombianos, congolenses, libaneses, iraquianos, liberianos, paquistaneses e de pessoas provenientes de Serra Leoa. Os refugiados no Brasil também enfrentam dificuldades, como acessar os serviços públicos, em especial, saúde e educação, ingressar em programas sociais, obter trabalho formal (Vieira; Menezes; Silva, 2017; Brasil, 2016).

A participação na educação proporciona fator de proteção. Embora esses benefícios possam apoiar o desenvolvimento dos países que acolhem e dos países de origem, a falta de acesso à educação pode levar à pobreza, desigualdade e alienação. Com a população de refugiados em idade escolar crescendo em média 600.000 pessoas por ano desde 2011, muitos países anfitriões precisam de apoio adicional para atender às necessidades educacionais. Em 2016, mais de 4.300 refugiados receberam bolsas de um programa de educação superior do ACNUR, apoiado pela Alemanha, para realizar o ensino superior em 37 países anfitriões. Mas para dezenas de milhares, tarifas, distância e a dificuldade de 
completar o ensino secundário conspiraram para excluí-los (UNHCR, 2017a; ACNUR, 2017a; G1 Triangulo Mineiro, 2017; UNHCR, 2016a).

No Brasil, nove instituições oferecem programas específicos para facilitar o acesso desses alunos. Cerca de 70 refugiados ingressaram em 17 instituições de ensino superior brasileiras entre novembro de 2016 até setembro de 2017. A Assembléia Legislativa do Estado de São Paulo aprovou o Projeto de Lei 557/2016, que prevê que os refugiados não paguem impostos para a revalidação de diplomas de graduação, mestrado e doutorado em universidades estaduais em São Paulo. A decisão, que levará à facilitação do processo de integração dos refugiados no Brasil, permitindo-lhes ter acesso ao mercado de trabalho de acordo com seus respectivos treinamentos e também eles podem continuar seus estudos, melhorar sua preparação, compartilhar seus conhecimentos e contribuir de forma mais assertiva para o desenvolvimento do Brasil. (Pachioni, 2017; São Paulo, 2016; G1 Triangulo Mineiro, 2017).

Este estudo tem por objetivo analisar o acesso ao ensino superior nas populações de refugiados a nível mundial. A pesquisa parte de uma pergunta norteadora baseada no acrônimo PICo (P, (população) refugiados; I, (interesse) processo educacional; e Co, (contexto) ensino superior): Como é o acesso dos refugiados à educação superior no mundo?

As taxas acadêmicas, as barreiras linguísticas e a falta de documentação representam, para a maioria dos jovens requerentes de asilo, a impossibilidade de continuar a estudar nos países de acolhimento. Mais de 80 por cento dos refugiados são alojados em países em desenvolvimento onde os serviços de educação muitas vezes não atendem satisfatoriamente as necessidades dos cidadãos (Unhcr, 2017b; Acnur, 2017b; G1, Triangulo Mineiro, 2017; Unhcr, 2016b). Assim, a hipótese é que, embora existam avanços e acordos firmados desde 1951 até a atualidade, o elevado número de refugiados que cruzam as fronteiras dos seus países tentando preservar suas vidas dificultam muito o acesso a esse bem. Além disso, deve-se considerar que boa parte dessas pessoas não conseguem ser reconhecidos como refugiados, seja por falta de documentos ou em decorrência da burocracia dos países que os acolhem. 


\section{Método}

Esta revisão sistemática usou o protocolo PRISMA (http://www.prismastatement.org/) para preparar a revisão e a meta-análise. Utilizou-se, durante a pesquisa, algumas etapas, tais como a escolha da linha de pesquisa e a elegibilidade do modo de pesquisa e dos artigos, análise das descobertas para definir quais os artigos comporão a amostra, e interpretação de dados com base nos objetivos do estudo.

A pergunta norteadora ancora-se no acrônimo PICO, em que a População é composta pelos refugiados; o Interesse é o processo educacional; e o Contexto é o ensino superior. Resultando na seguinte pergunta orientadora: Como é o acesso dos refugiados à educação superior no mundo? Os jornais da Figura 1 foram utilizados para dados pesquisa.

Figura 1. Jornais usados para pesquisa. Fonte: Desenvolvido pelos atores

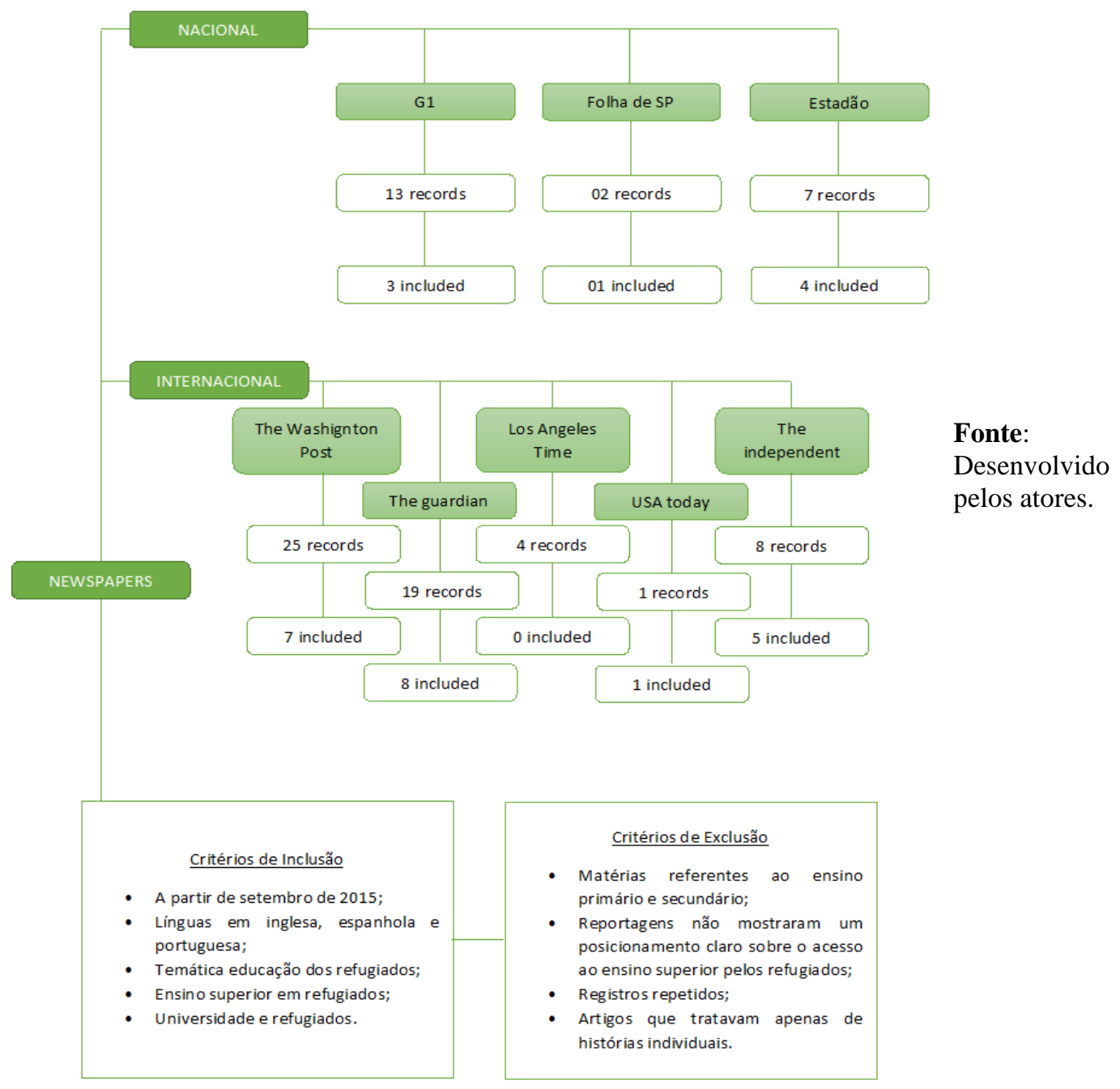




\section{Resultados}

Um total de 6.768 reportagens foram encontradas em 8 jornais digitais de grande visualização, sendo 573 no G1; 59 na Folha de São Paulo; 1087 no The Washington Post; 4380, The Guardian; 152 no Los Angeles Time; 1 no USA Today; 157 no Estadão; e 359 no The Independent. Destes, 6.739 reportagens foram excluídas por apenas mencionaram ou se referirem aos refugiados, não analisarem a educação no nível superior nessa população, abordaram apenas relatos isolados de pessoas que tiveram acesso ao ensino superior ou foram repetidos. A Figura 2 resume o processo metodológico da seleção de artigos.

O Gráfico 1 inclui um resumo global das descobertas nos jornais investigados. No meio dos conflitos e enfrentando o perigo eminente da morte fazem com as pessoas decidam fugir dos seus países sem terem tempo de planejarem a viagem. A Figura 3 e a Figura 4 mostram a quantidade de reportagens incluídas e o acesso ao ensino superior por parte dos refugiados; e a Figura 5 mostra as principais universidades que acolhem os refugiados citadas nos jornais internacionais e nacionais.

Figura 2. Jornais usados para a pesquisa.

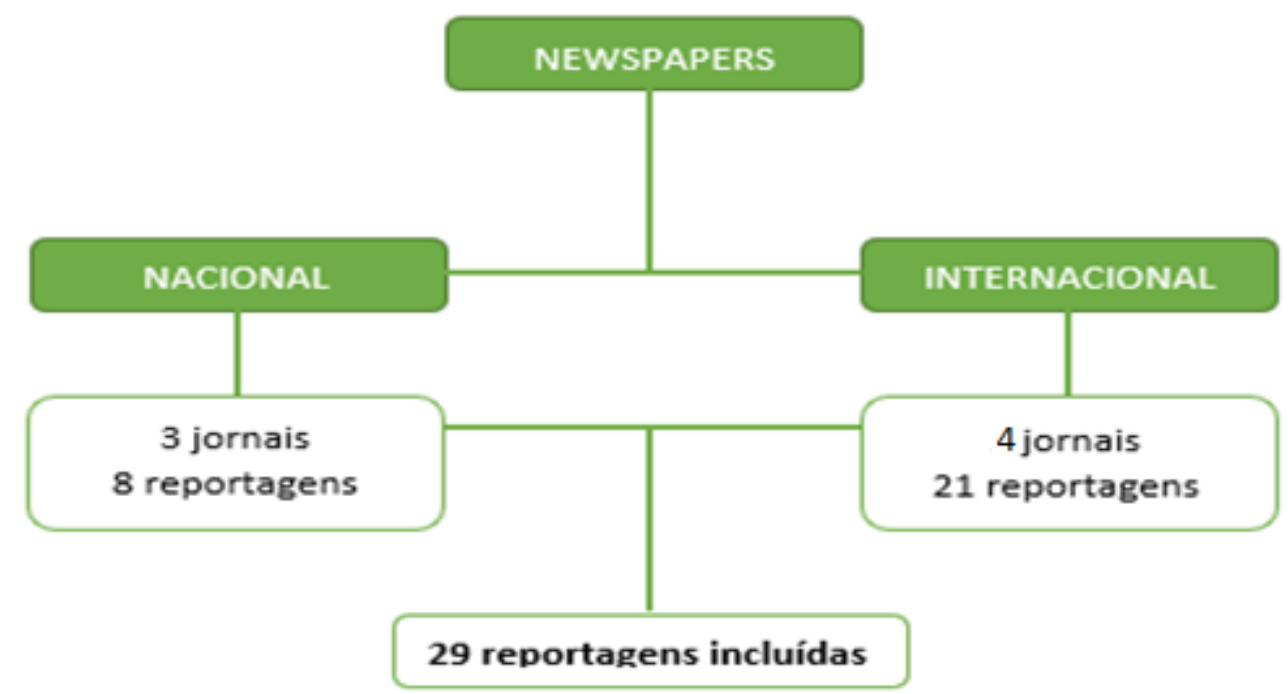

Fonte: Desenvolvido pelos autores. 
Um total de 79 reportagens foram escolhidas por quatro pesquisadores na primeira triagem. Dessas, 29 foram selecionadas pelos outros dois pesquisadores, sendo incluídos nesta pesquisa: 3 do G1; 1 do Folha de São Paulo; 4 do Estadão; 7 do The Washignton Post; 1 USA Today; 8 do The Guardian; e 5 do The Independent.

Figura1. Diagrama de fluxo do processo de elegibilidade das reportagens .

Figural. Diagrama de fluxo do processo de elegibilidade das reportagens .

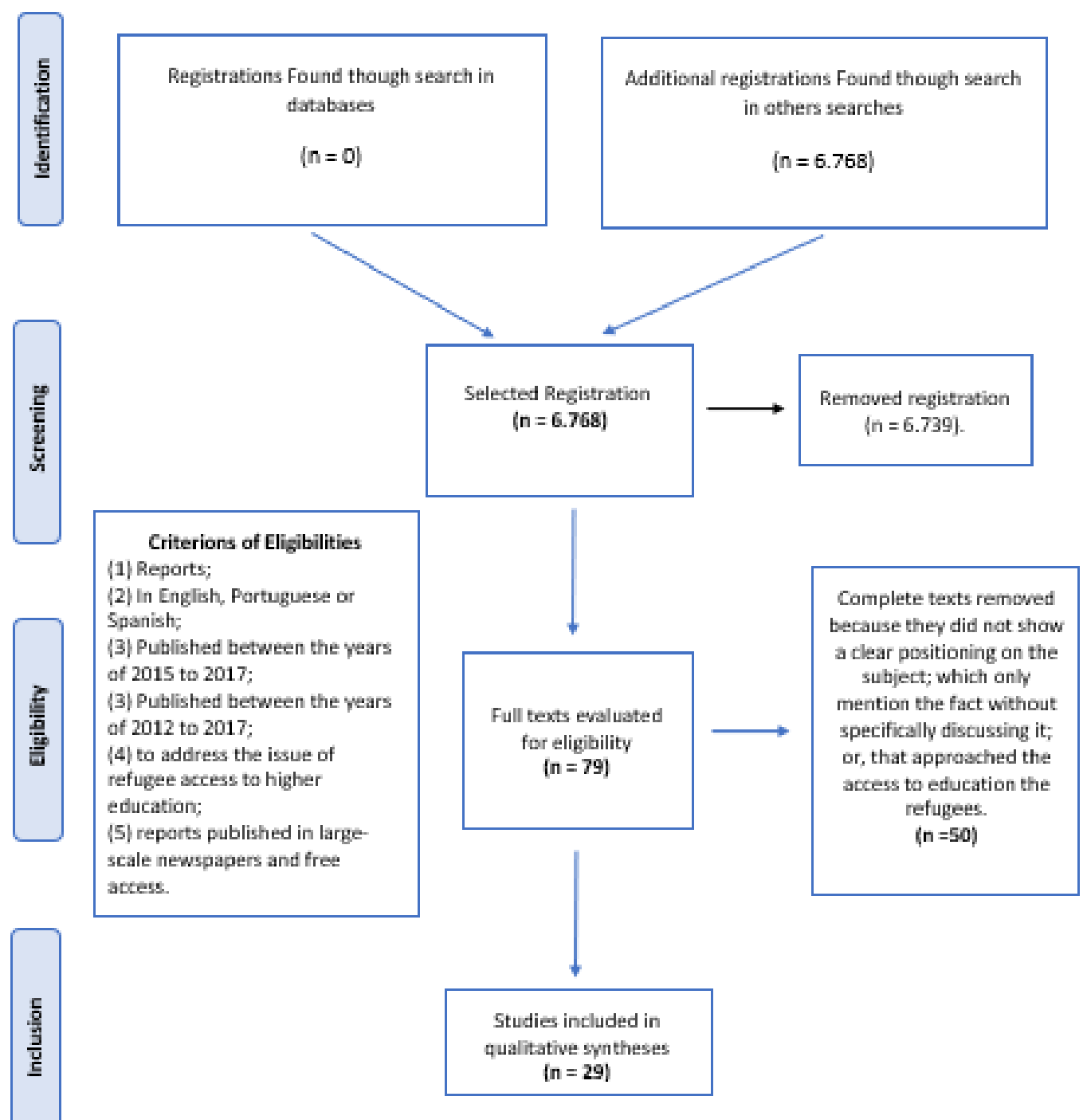

Figure 2. Flowchart of study gearch. Source: Developed by the authors. 


\section{Acesso dos Refugiados à Educação Superior}

Tabela 1 - Principais Achados.

\begin{tabular}{cl}
\hline NewSpaper & \multicolumn{1}{c}{ Main approach } \\
\hline & $\begin{array}{l}\text { A Universidade de Glasgow anunciou que oferecerá quatro novas bolsas } \\
\text { para refugiados, uma em cada uma das faculdades. O Citizen UK convidou } \\
\text { as universidades britânicas a fornecer lugares para refugiados e iniciou } \\
\text { uma petição pedindo às universidades que ofereçam 10 bolsas cada. A }\end{array}$ \\
& $\begin{array}{l}\text { Universidade de East London também está oferecendo bolsas de estudo } \\
\text { para refugiados sírios, com todas as taxas pagas. As universidades do }\end{array}$ \\
The Guardian & Reino Unido estão intensificando a assistência a essa população. \\
(2015) & $\begin{array}{l}\text { Significativamente, isso envolveu estudantes e funcionários. Mas a } \\
\text { realidade é que nem todos são assistidos. Estudantes de Oxford }\end{array}$ \\
& aproveitaram organizaram uma marcha pela cidade para exigir um melhor \\
& tratamento dos refugiados. Muitas universidades agora oferecem bolsas de \\
& estudo anualmente para aqueles que estão fugindo do conflito, incluindo a \\
& Universidade de East London, York e Warwick. \\
& $\begin{array}{l}\text { Cerca de 90 \% dos iranianos que participaram do exame de competências } \\
\text { completaram o treinamento e a educação posterior depois de deixar o } \\
\text { ensino médio. Quase 70 \% dos sírios fizeram o mesmo. Em torno de 40\% } \\
\text { dos refugiados do Irã e do Iraque tinham títulos universitários.Cerca de } 60\end{array}$ \\
universidades alemãs estão oferecendo aos refugiados a oportunidade de \\
participar de cursos como estudantes convidados, sem cobrar taxas. \\
Alemanha oferece uma taxa de matrícula gratuita para todos os que estão \\
no país legalmente porque precisa atrair trabalhadores mais qualificados \\
para atender à sua alta demanda e baixo desemprego
\end{tabular}

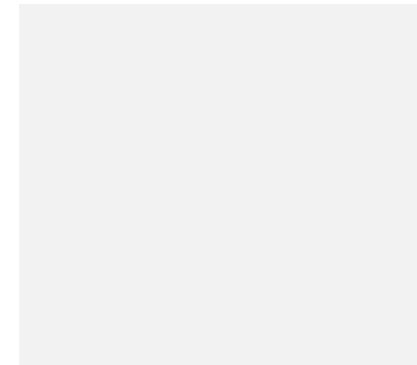

The Independent 2015

USA Today 2015
O Estadão 2017

A Universidade de Kiron, Berlim, pode ser acessada de qualquer lugar oferecendo graus de bacharel em cinco áreas. As universidades na GrãBretanha estão sendo chamadas a ajudar os refugiados e aos requerentes de asilo a acessarem o ensino superior. Refugiados e requerentes de asilo no Reino Unido estão sendo convidados a estudar em uma universidade londiniana gratuitamente. A Universidade de East London ofereceu 10 bolsas de estudo para os sírios que se abrigam em campos de refugiados, enquanto a Universidade de Sheffield está oferecendo bolsas de estudo para estudantes da Síria mostrando "potencial acadêmico excepcional". A Universidade de York lançou um pacote de iniciativas de $£ 500,000$ para ajudar os refugiados, incluindo bolsas de estudo, e a Universidade de Warwick também ofereceu 20 bolsas de estudo. A Universidade de Londres do Leste deve lançar um novo curso curto conhecido como Iniciativa de Aprendizagem Aberta (OLIve) que dará aos refugiados e requerentes de asilo a base educacional para progredir para um curso de fundação e, finalmente, um bacharelado completo Há uma demanda real de apoio educacional entre os refugiados, que muitas vezes não conseguem acessar o trabalho remunerado e a educação formal ou solicitar apoio financeiro.. As universidades britânicas ofereceram bolsas de estudo aos refugiados que procuram ingressar no ensino superior. É importante reconhecer os direitos humanos da educação além das fronteiras nacionais

Mostra uma incitava de uma Universidade Alemã que oferece cursos universitários on line com duração de 2 anos a refugiados.

A Universidade de Stanford nos EUA e a Universidade de Edinburgo na Escócia oferecerão aos refugiados de todo o mundo acesso a mais de mil cursos universitários gratuitos pela Internet. Apenas $1 \%$ dos refugiados têm acesso ao nível superior. Há programa de reserva de vagas nas 
Universidades brasileiras para refugiados, em cada um dos cursos voltadas somente para refugiados e migrantes em situação de vulnerabilidade. O número de universidades que oferecem algum tipo de auxílio aos refugiados cresce a cada ano. Ao menos 17 instituições do País, públicas e privadas, já integram um grupo liderado pela Acnur, com ações que vão de benefícios no vestibular, como cotas, a auxílio financeiro, aulas de português e ajuda com documentações. Nesse não é solicitado o vestibular, mas sim o comprovante de refúgio ou, no caso do migrante, da situação socioeconômica. Os candidatos também precisam comprovar, de alguma forma, que concluíram o ensino médio. Além disso, há a possibilidade de solicitar reconhecimento de disciplinas já cursadas no exterior.

Cerca de 70 refugiados ingressaram em 17 instituições de ensino superior brasileiras entre novembro de 2016 até setembro de 2017. No mundo todo, um

G1 refugiado tem 36 vezes menos chance de ingressar no ensino superior do que 2017 alguém que não está em situação de refúgio. Aponta que no mundo todo só $1 \%$ dos refugiados chega à faculdade; e no Brasil nove instituições oferecem programas específicos para facilitar o acesso desses alunos.

Folha de São Paulo Aborda a criação de um programa-piloto que oferecer a 400 estudantes no 2016 campo refugiado de Dadaab, no norte do Quênia, a oportunidade de conquistar diplomas universitários.

Fonte: Desenvolvidos pelos autores, 2019.

\section{Discussão}

\section{Refugiados X Ensino Superior: Panorama Geral}

A crise dos refugiados é notória e percebida por todo o mundo, em resposta há mobilizações humanitárias e também no meio acadêmico como já pode ser visto anteriormente no caso das universidades norte americanas e também nas universidades da Grã-Bretanha, onde um grupo acadêmico escreveu uma carta aberta ao vice-chanceler propondo abertura de bolsas de graduação e pós-graduação para refugiados vítimas da violência e da guerra, juntamente a eles há grupos religiosos e ativistas que lutam pela causa e financiam bolsas e taxas de matrículas para estudantes asilados (Kirby, 2015; Pells, 2017).

Em todo o mundo, os refugiados possuem 36 vezes menos chance de ingressar no ensino superior do que alguém que não está em situação de refúgio. Apenas $1 \%$ da população de refugiados chega à faculdade. (Bazzo, Fajardo, 2017; Toledo, 2017; Fleming, 2016). Segundo dados da universidade alemã de Kiron, atualmente cerca de oito milhões de pessoas iniciaram os estudar, ou gostariam de entrar na universidade e foram impedidas de continuar por circunstâncias em seus países de origem por razões que os condenavam a procurar refugio. Dos cerca de 60 milhões de refugiados em todo o mundo, cerca de 
metade são menores de 18 anos. Esses jovens necessitam de ajuda para continuar imediatamente com a educação. (Ali, 2015; Yohannes, Bhatti, 2015).

Uma agência do governo austríaco realizou um pesquisa, e descobriu que muitos requerentes de asilo do Oriente Médio tinham níveis de educação que, em alguns casos, eram superiores aos da maioria dos austríacos fora do trabalho. Cerca de $90 \%$ dos iranianos que participaram do exame de competências completaram o treinamento e a educação posterior depois de deixar o ensino médio. Cerca de $70 \%$ dos sírios fizeram o mesmo. Cerca de $40 \%$ dos refugiados do Irã e do Iraque tinham títulos universitários. (Tharoor, 2016).

Na França, os jovens são enviados para a escola e a universidade por muitas razões: para que sejam academicamente curiosos, desenvolvam sua capacidade crítica de pensar, explorem novas ideias, adquiram os meios para realizar suas ambições e aspirações. $\mathrm{Na}$ verdade, em países ricos, um governo que não oferece educação para o seu povo é considerado incompetente. $\mathrm{O}$ investimento em educação em regiões de conflito, segundo o relatório da ONU, não passa de $2 \%$ do orçamento do País, muito abaixo do mínimo recomendável de 5\%. A universidade é uma chance de recomeço a longo prazo. É uma prioridade para o ACNUR e suas organizações parceiras - por isso, desenvolvem programas de educação acelerada para permitir que os aprendizes em excesso se recuperem e se juntem ao currículo, por que encorajamos os ministérios da educação a incluir as crianças refugiadas em seus sistemas educacionais nacionais com as mais eficazes e sustentáveis maneiras de garantir que eles são ministrados por professores experientes e recebe, qualificações credenciadas (Fleming, 2016; Bazzo,. Fajardo, 2017; Toledo, 2017).

O campo de refugiados de Dadaab, no norte do Quênia, abriga cerca de 500 mil pessoas, fazendo do lugar o maior complexo de refugiados do mundo. Lá existe acesso a aulas do ensino primário e secundário, mas, para além disso, as oportunidades educacionais têm sido muito limitadas. Um programa-piloto foi criado para oferecer a 400 estudantes dos campos a oportunidade de conquistar diplomas universitários e de licenciatura. A ideia surgiu de um programa do World University Service of Canada, que já ofereceu bolsas de estudo em universidades canadenses a 1.350 refugiados de todo o mundo nos últimos 35 anos. As aulas serão presenciais e on-line. Os estudantes estarão em contato também com mentores no Canadá e no Quênia. Do primeiro grupo de estudantes, $17 \%$ eram mulheres, refletindo o fato de que as garotas tendem a abandonar o ensino secundário devido a pressões familiares e religiosas. $\mathrm{O}$ ensino superior oferece uma 
alternativa e dá aos jovens a oportunidade de mudar sua visão do campo de refugiados, uma chance, quem sabe, de voltar a seu país e reconstruí-lo (Brownell, 2016).

Na Universidade de Damasco na Síria, em virtude da revolta, um grande número de acadêmicos foram mortos, torturados, raptados ou forçados a deixarem o país para salvar suas vidas e suas famílias. Assim, o financiamento desapareceu e falta de instalações e equipamentos de pesquisa, como também, escassez mais fundamental de recursos básicos, como eletricidade, combustível e água. Algumas universidades tiveram que mudar para edifícios temporários que não são adequados para o ensino, e muito menos para hospedar instalações de pesquisa. (Anonymous Academic. 2016).

Segundo o UNHCR é necessário investimento em bolsas de estudo e programas para obter os refugiados do ensino médio para a universidade. Como também treinamento técnico e profissional para promover habilidades e melhorar as perspectivas de emprego. (Fleming, 2016).

\section{Refugiados X Ensino Superior: Brasil}

No Brasil, segundo o Conare (Comitê Nacional para os Refugiados), a população de refugiados é formada por 9.552 pessoas de 82 nacionalidades (G1, 2017a). Os dados dos números de refugiados que conseguem ingressar numa instituição em ensino superior não são conhecidos, isto se deve ao fato deles poderem estar matriculados em outras instituições que não estão entre as 17 "parceiras" da Acnur. As universidades brasileiras que integram a chamada "Cátedra Sérgio Vieira de Mello" estão engajadas em diversos projetos com pesquisas e ações, as quais envolvem assistência jurídica, apoio na área da saúde, programas específicos de acessibilidade ao ensino superior, políticas de permanência, ensino da língua portuguesa entre outros (Bazzo, Fajardo, 2017).

Para o ingresso em instituições de ensino superior com programas de acesso para refugiados, os candidatos devem comprovar a situação de refugiado, por meio de atestado emitido pelo Conare e que já tenham concluído o Ensino Médio ou equivalente. Segundo dados do Acnur, cerca de 70 refugiados ingressaram em 17 instituições de ensino superior brasileiras entre novembro de 2016 até setembro de 2017. Durante este período, 22 diplomas de refugiados foram revalidados por estas mesmas instituições (G1, 2017a).

As universidades parceiras da Acnur são: Pontifícia Universidade Católica de São Paulo (PUC -SP); Universidade Católica de Santos (Unisantos); Universidade de Vila 
Velha (UVV); Universidade Estadual do Rio de Janeiro (UERJ); Universidade do Vale do Rio dos Sinos (Unisinos); Universidade Estadual da Paraíba (UEPB); Universidade Federal da Grande Dourados (UFGD); Universidade Federal de Roraima (UFRR); Universidade Federal de Santa Catarina (UFSC); Universidade Federal de Santa Maria (UFSM); Universidade Federal de São Carlos (UFSCar); Universidade Federal do ABC (UFABC); Universidade Federal do Espírito Santo (Ufes); Universidade Federal do Estado de São Paulo (Unifesp); Universidade Federal do Paraná (UFPR); Fundação Casa de Ruy Barbosa (FCRB) e Universidade Federal do Rio Grande do Sul (UFRGS). Algumas delas oferecem programas específicos para facilitar o acesso de refugiados (Bazzo, Fajardo, 2017).

Essas universidades oferecem ações que vão de benefícios no vestibular, como cotas, a auxílio financeiro, aulas de português e ajuda com documentações ao acesso à Casa do Estudante e alimentação gratuita. No primeiro ano da iniciativa, ao menos 50 candidatos tentam ingresso na instituição por esta modalidade, que não solicita o vestibular, mas sim o comprovante de refúgio ou, no caso do migrante, da situação socioeconômica. Os candidatos também precisam comprovar, de alguma forma, que concluíram o ensino médio (Toledo, 2017).

Dados da Cáritas, confederação de 162 organizações humanitárias da Igreja Católica, apontam que cerca de $25 \%$ dos refugiados possuem curso superior completo. Como o Brasil não apresenta uma legislação específica sobre o tema, as universidades públicas brasileiras responsáveis pela validação estabelecem suas próprias regras, em um processo que pode levar até dois anos e custar até 1000 reais, o Ministério da Educação chegou a emitir ditame para flexibilizar a validação de diplomas (Rossetto, 2016).

\section{Refugiados X Ensino Superior: Europa}

Centenas de milhares de refugiados que chegam na Europa a partir do Oriente Médio, Ásia e África colocaram suas vidas em perigo em busca de futuros mais seguros e prósperos. Muitos não têm os fundos ou habilidades de língua inglesa para reiniciar sua educação (Yohannes, Bhatti, 2015). O papel do ensino superior no apoio ao progresso social ainda é visto muitas vezes simplesmente através da lente de acesso. Há uma enorme quantidade de instituições que estão apoiando e capacitando comunidades além do campus, abordando diretamente os desafios mais difíceis da sociedade, como a crise dos refugiados (Huntley, 2016). 
Uma universidade alemã de Kiron começou a oferecer, em outubro de 2015, aulas on-line para cerca de 1.000 estudantes refugiados em todo o mundo que aguardam o status oficial de asilo para permanecerem em seus países de acolhimento. Isso proporcionará muitos refugiados com créditos para que possam ser transferidos para 35 universidades parceiras em toda a Europa. Atualmente, cada aluno dos cursos de dois anos de Kiron custa US \$ 1.363, esses custos são financiados por uma fundação alemã. No futuro, os graduados da Kiron que ganhem mais de US \$ 33.300 por ano podem se voluntariar para pagar 5\% do seu salário durante cinco anos para ajudar a pagar a próxima geração. No entanto, a aprendizagem on-line no Oriente Médio não está bem desenvolvida, muitos refugiados não possuem habilidades básicas de informática (Yohannes, Bhatti, 2015).

Cerca de 60 universidades alemãs estão oferecendo aos refugiados a oportunidade de participar gratuitamente de cursos como estudantes convidados. Eles também oferecem transporte e bolsas de estudo para pagar livros. Cada estudante custa ao governo alemão cerca de US \$ 10.000 por ano. Embora os imigrantes permaneçam incapazes de obter diplomas enquanto seus pedidos de asilo estão sendo processados, assistir às palestras sob o novo esquema deve permitir que eles aprendam alemão mais rápido e completem cursos. Se o pedido de asilo de um refugiado for aceito pelas autoridades, é possível continuar os cursos selecionados como um estudante e receber o diploma (Asquith, 2015; Noack, 2015).

A entrada maciça de 800 mil refugiados na Alemanha derrubou a popularidade de Ângela Merkel, apesar disso, a primeira-ministra insiste que é dever cívico e humanitário assistir os que fogem da morte em seus países de origem. Mas, além do louvável altruísmo, há uma importante razão econômica, a necessidade de atrair trabalhadores mais qualificados para atender à sua alta demanda de mão de obra. Como a grande maioria dos migrantes é proveniente de países mais pobres, com educação e formação profissional precárias, o governo colocou os jovens migrantes com baixa escolaridade aprendendo alemão à noite e trabalhando como estagiários e em serviços de baixa qualificação durante o dia. Para os mais educados, as escolas profissionais e universidades abriram vagas na medida do possível. Estima-se que entre 30.000 e 50.000 refugiados foram elegíveis para estudar na Alemanha em 2016. Pode ser difícil para os refugiados entrarem no ensino superior devido a questões de visto, língua e financiamento (Young-Powell, 2015; Pastore, 2015).

As universidades britânicas responderam à crise dos refugiados oferecendo bolsas de estudo aos refugiados que desejam ingressar no ensino superior. Muitos anunciaram 
bolsas de estudo para estudantes de refugiados, incluindo Warwick, York, Sussex, Edimburgo, London School of Economics, a Escola de Estudos Orientais e Africanos e a Universidade de East London. Em Middlesbrough, que abriga a segunda maior comunidade britânica de refugiados e requerentes de asilo fora de Londres, a Universidade Teesside está ajudando as pessoas marginalizadas e vulneráveis a participa da sociedade. Significativamente, isso envolveu estudantes e funcionários, que também podem se beneficiar dos talentos e conhecimentos dos refugiados e requerentes de asilo. O impacto das universidades na criação de uma sociedade melhor vai além dos que trabalham e estudam dentro de seus muros, elas devem ser participantes ativos, com o objetivo de abordar a desigualdade através de ações. É importante reconhecer os direitos humanos da educação além das fronteiras nacionais. O acesso ao ensino superior permite que os indivíduos desenvolvam seus talentos e utilizem-nos para contribuir com as sociedades que lhes proporcionam abrigo (Doré, 2015; Lock, Niemtus, 2015; Huntley, 2016).

Uma petição on-line que faz campanha para todas as universidades para oferecer oportunidades aos refugiados atraiu 600 assinaturas em duas semanas. O apelo, apoiado pela caridade Citizens UK e a Campanha para a Universidade Pública, exige uma resposta a todo o setor. A Universidade de York destinou $£$ 500,000 para bolsas de graduação ao longo de três anos e estabeleceu uma parceria com o Instituto de Educação Internacional para trazer dois acadêmicos para a cidade. Em tempos como este, manter oportunidades de educação superior disponíveis é crucial porque trabalhadores qualificados e universidades desempenham um papel importante na reconstrução dos países após o conflito.

Hoje, a Universidade de East London tem estudantes de mais de 125 países, incluindo estudantes da Síria. Os refugiados terão que cumprir os mesmos requisitos de entrada que o resto dos alunos e eles também terão que cumprir as exigências das autoridades de imigração. Esses alunos terão passado por circunstâncias particularmente difíceis, mas isso não deve impedir que aprendam. Enquanto isso, o Conselho de Pesquisa Econômica e Social (ESRC) e o Departamento de Desenvolvimento Internacional forneceram uma "concessão de urgência" de $£ 1 \mathrm{~m}$ para pesquisas sobre a crise. Isso será usado para financiar oito projetos em seis universidades: Coventry, Durham, Middlesex, Warwick, York e Queen Mary, Universidade de Londres (Asquith, 2015) (Lock, Niemtus, 2015) (Pujol-Mazzini, 2016).

The Council for At Risk Academics -Cara, é uma instituição de caridade do Reino Unido criada em 1933, desde então, tem ajudado acadêmicos de todo o mundo, 
impulsionados pelo desejo humanitário de aliviar o sofrimento, mas também pela necessidade de defender o aprendizado, para proteger a riqueza de inteligência de uma nação, entendendo que será necessário para ajudar a reconstruir países uma vez que as guerras terminaram. Atualmente, a Cara trabalha com 110 universidades do Reino Unido e ajudou 140 pessoas, mais 200 dependentes. Os acadêmicos ajudados atualmente são predominantemente da Síria. Ela combina-se com uma universidade patrocinadora e contribui para os custos de vida e facilitando aplicações laborais de visto. Os candidatos a este esquema devem satisfazer os rigorosos requisitos de entrada do Reino Unido, alguns são inicialmente rejeitados (SHABI, 2015).

\section{Refugiados X Ensino Superior: USA}

Nos USA, a situação nos campi é melhor caracterizada como cheia de incerteza, confusão e medo. A ordem executiva assinada pelo presidente Donald Trump inclui uma proibição de entrada nos Estados Unidos por cidadãos de sete países predominantemente muçulmanos - Irã, Iraque, Líbia, Somália, Sudão, Síria e Iêmen - nos próximos 90 dias e proibições temporárias de refugiados, inclusive um bloqueio indefinido sobre os da Síria. Trump argumentou que a proibição é necessária para garantir que os Estados Unidos sejam protegidos de extremistas estrangeiros que desejam entrar no país e prejudicar os americanos. Cerca de 1 em cada 20 dos mais de 20 milhões de estudantes matriculados em faculdades dos EUA em 2015-2016 vem do exterior, de acordo com o Instituto de Educação Internacional, com cerca de 17 mil deles originários dos sete países incluídos na proibição, mais de 12 mil deles são iranianos (G1, 2017; Svrluga, 2017; Svrluga, 2017; Strauss, 2017; Mcpherson, 2017).

Quando a proibição foi anunciada, os líderes universitários foram alguns dos adversários mais abertos da medida, advertindo que isso dificultaria a pesquisa e o recrutamento dos melhores talentos no mundo. A imigração tem sido uma fonte de criatividade e força para este país ao longo de sua história. É indispensável a missão e a excelência das universidades americanas, que melhoram a economia, a segurança e o bemestar deste país através dos alunos que eles educam e das ideias que geram. A Associação de Colégios Médicos Americanos, afirmou em uma declaração de que eles estão profundamente desapontados com o fato de a ordem revista não reconhecer explicitamente a importância dos diplomados, médicos e pesquisadores médicos internacionais na 
segurança da saúde do país e solicitou isenções e outros subsídios para profissionais de saúde desses países. As universidades dos EUA se destacam, em parte, por sua capacidade de se conectar em todo o mundo, essa ordem mina isso (Svrluga, 2017; Mcpherson, 2017; G1, 2017; Strauss, 2017).

O Supremo Tribunal concordou em permitir que uma versão limitada da proibição entre em vigor, criando exceções que parecem isentar estudantes universitários, professores e palestrantes. Pode haver um efeito de ondulação em estudantes internacionais que desejam estudar nas universidades americanas em geral. O caso aborda questões de segurança nacional e discriminação religiosa (Svrluga, 2017; Mcpherson, 2017).

Há uma série de bolsas de estudo disponíveis para imigrantes e americanos nascidos no exterior. Faculdades e universidades em todo os Estados Unidos estão lutando para ajudar estudantes e estudiosos afetados pela proibição. Massachusetts anunciou uma nova bolsa para um estudante internacional afetado pelo pedido de imigração do presidente Trump. A bolsa de estudos de Wheaton Refugee oferecida pela escola de artes liberais com cerca de 1.600 alunos cobrirá todos os custos de comparecer à faculdade em Norton, Massachusetts. A Universidade Roger Williams, uma escola semi-privada de artes liberais em Rhode Island, ofereceu quatro bolsas de estudo - duas para a faculdade de direito e duas para a escola de arquitetura - para estudantes da Síria, devastada pela guerra. Princeton continuará a apoiar estudantes, professores e funcionários de todas as nacionalidades e fé, e a defender políticas que respeitem simultaneamente os legítimos interesses de segurança desta nação e permitam o movimento livre e vital de estudantes e estudiosos através das fronteiras. Esses alunos enfrentaram dificuldades extraordinárias e acreditamos que é nossa responsabilidade como educadores globais assumirem esse compromisso neste momento (Svrluga, 2017; Strauss, 2017).

Uma iniciativa proporciona acesso gratuito pela internet a mais de mil cursos universitários em escolas como a Universidade de Stanford nos EUA e a Universidade de Edinburgo na Escócia em áreas que vão da criação de códigos de computador à neurociência. Isso é possível graças a um esforço para oferecer educação e treinamento que é parte de um programa sediado nos Estados Unidos e que foi lançado no Dia Mundial dos Refugiados. O programa, lançado conjuntamente com o Departamento de Estado dos EUA, permitirá que organizações sem fins lucrativos (ONGs) se inscrevam para receber auxílio financeiro para que os refugiados estudem de graça. A expectativa é que nos primeiros meses o programa atraia centenas de refugiados e se espera que essa cifra cresça 
rapidamente para milhares à medida que outras ONGs se inscreverem. Os cursos são ofertados pela empresa Coursera através do site siterefugees.coursera.org (O ESTADO DE S. PAULO. 2016).

\section{Conclusão}

A crise dos refugiados é percebida por todo o mundo, em resposta há mobilizações humanitárias, de grupo religiosos, ativistas e também no meio acadêmico, propondo abertura de bolsas de graduação e pós-graduação para refugiados vítimas da violência e da guerra (Kirby, 2015; Pells, 2017;). No mundo, os refugiados possuem 36 vezes menos chance de ingressar no ensino superior do que alguém que não está em situação de refúgio (Bazzo, Fajardo, 2017; Toledo, 2017; Fleming, 2016).

Em países ricos, um governo que não oferece educação para o seu povo é considerado incompetente. Então, por que não conseguimos fazer isso com os refugiados? O investimento em educação em regiões de conflito está muito abaixo do mínimo recomendável de $5 \%$ pela ONU. A universidade é uma chance de recomeço a longo prazo (Fleming, 2016; Bazzo, Fajardo, 2017; Toledo, 2017).

Há uma enorme quantidade de instituições estão apoiando e capacitando comunidades além do campus, abordando diretamente os desafios mais difíceis da sociedade, como a crise dos refugiados. (Yohannes, Bhatti, 2015). Cerca de 60 universidades alemãs estão oferecendo aos refugiados a oportunidade de participar gratuitamente de cursos como estudantes convidados. (Asquith, 2015; Noack, 2015). As universidades britânicas também estão oferecendo bolsas de estudos aos refugiados que desejam ingressar no ensino superior (Doré, 2015; Lock, Niemtus, 2015; Huntley, 2016; Shabi, 2015).

Nos USA, a situação nas universidades é melhor caracterizada como cheia de incerteza, confusão e medo. A ordem executiva assinada pelo presidente Donald Trump que proibiu a entrada nos Estados Unidos por cidadãos de sete países predominantemente muçulmanos nos próximos 90 dias gerou a comoção de líderes universitários e estudantes. Faculdades e universidades em todo os USA estão lutando para ajudar estudantes e estudiosos afetados pela proibição a partir do entendimento de que é responsabilidade dos educadores globais assumirem esse compromisso neste momento (Svrluga, 2017; Strauss, 2017; G1, 2017; Mcpherson, 2017). 


\section{Referências}

ACNUR (2016). Missing out refugee education in crisis. September.

ACNUR (2017). Executive Committee of the High Commissioner's Programme. Standing Committee, 69th meeting, 07 de jun de 2017. [Acesso 13 de janeiro de 2018]. Disponível em: http://www.unhcr.org/excom/standcom/593917957/update-on-education.html?query= Refugee\%20education.

ACNUR (2018). ACNUR pide más plazas de reasentamiento para refugiados después de la muerte de 160 personas en el Mediterráneo. ACNUR, la agencia de la ONU para los refugiados, 12 de janeiro de 2018. [Acesso 13 de janeiro de 2018]. Disponível em: http://www.acnur.org/noticias/noticia/acnur-pide-mas-plazas-de-reasentamiento-para refugiados-despues-de-la-muerte-de-160-personas-en-el-mediterraneo/.

Ali, A. (2016) University of Edinburgh to provide fully-funded scholarships and 'significant reduction' in costs to asylum-seeking students. The Idependent. http://www.independent.co.uk/student/news/university-of-edinburgh-to-provide-fullyfunded-scholarships-and-significant-reduction-in-costs-to-a6850541.html.

Anonymous Academic. (2016). I fled Syria for Kent - and regained my life as an academic. The Guardian. https://www.theguardian.com/higher-educationnetwork/2016/jul/15/i-fled-syria-for-kent-and-regained-my-life-as-an-academic.

Antunes, Claudia; Romero, Gabriela (2018). As 136 milhões de pessoas deixadas para trás. El país, 1 jan de 2018. [Acesso 13 de janeiro de 2018]. Disponível em: https://brasil.elpais.com/brasil/2017/12/29/opinion/1514584894_638728.html.

Asquith, Shelly. (2015). Students demonstrate support for the plight of refugees. The Guardian. https://www.theguardian.com/education/2015/sep/17/students-demonstratesupport-for-the-plight-of-refugees after-they-graduate/?utm_term=.0b0697807a61.

Bazzo, G. and Fajardo, V. (2017) Universidades brasileiras matricularam cerca de 70 refugiados em menos de um ano, diz Acnur. Educação, G1. https://g1.globo.com/educacao/noticia/universidades-brasileiras-matricularam-cerca-de 70-refugiados-em-2016-diz-acnur.ghtml.

Brasil, Cidadania e Justiça. Brasil abriga 8.863 refugiados de 79 nacionalidades [Acesso 13 de janeiro de 2018]. Disponível em: http://www.brasil.gov.br/cidadania-ejustica/2016/05/brasil-abriga-8-863-refugiados-de-79-nacionalidades.

Brownell, Ginanne. (2016). Faculdade chega aos campos de refugiados no Quênia. Folha de São Paulo. https://www1.folha.uol.com.br/fsp/newyorktimes/135023-faculdade-chegaaos-campos-de-refugiados-no-quenia.shtml?loggedpaywall\#_=_.

Doré, Louis. (2015). These UK universities are offering scholarships to refugees The Independent. https://www.indy100.com/article/these-uk-universities-are-offering- 
scholarships-to-refugees--WkN5FAeFUldraw-the- brightest-minds- from-across- theworld- lets-stop- sending-them- home-

Fleming, Melissa. (2016). I want to be South Sudan's first female neurosurgeon' - the struggle for refugee education. https://www.theguardian.com/global-developmentprofessionals-network/2016/sep/19/struggle-education-refugee-education-south-sudan.

G1, São Paulo (2015). Foto chocante de menino morto revela crueldade de crise migratória. G1, 02/09/2015 15h57. [Access on: January 18/2018]. Available on: http://g1.globo.com/mundo/noticia/2015/09/foto-chocante-de-menino-morto-virasimbolo-da-crise-migratoria-europeia.html.

G1. (2017) Universidades temem que decreto de Trump contra imigrantes afete estudantes e pesquisadores. https://g1.globo.com/educacao/noticia/universidades-temem-que-decreto-de-trumpcontra-imigrantes-afete-estudantes-e-pesquisadores.ghtml.

G1. (2017a) UFTM divulga edital de processo seletivo para ingresso de refugiados na graduação em Uberaba e Iturama. Gl, Triangulo Mineiro. https://g1.globo.com/mg/triangulo-mineiro/noticia/uftm-divulga-edital-de-processoseletivo-para-ingresso-de-refugiados-na-graduacao-em-uberaba-e-iturama.ghtml.

Huntley, Gabriel. (2016). Brexit exposed deep rifts in Britain. Universities can help heal them. The Guardian. https://www.theguardian.com/higher-educationnetwork/2016/jul/27/brexit-exposed-deep-rifts-in-britain-universities-can-help-heal-them.

Kirby, D. (2015) Refugee crisis: British universities should create scholarships and bursaries for students fleeing violence, say academics. The Independent. http://www.independent.co.uk/news/education/higher/refugee-crisis-british-universitiesshould-create-scholarships-and-bursaries-for-students-fleeing-10511795.html;

Lock, Helen and Niemtus, Zofia. (2015). 'We want to be part of the solution': universities reach out to refugees. https://www.theguardian.com/higher-educationnetwork/2015/oct/02/universities-scholarships-jobs-offer-refugees.

McPherson, P. (2017). U.S. Universities draw the brightest minds from across the Word. Disponível em: https://www.aplu.org/news-and-media/in-the-news/us-universities-drawthe-brightest-minds-from-across-the-world-lets-stop-sending-them-home-after-theygraduate.

Noack, Rick (2015). Why some German universities will educate refugees for free. The Washigton Post. https://www.washingtonpost.com/news/worldviews/wp/2015/08/20/whysome-german-universities-will-educate-refugees-for-free/?utm_term=.e5339bf8d8ba.

O Estado de S. Paulo. (2016). EUA vão oferecer cursos universitários gratuitos online para refugiados. Estadão. http://internacional.estadao.com.br/noticias/geral,eua-vao oferecer-cursos-universitarios-gratuitos-online-para-refugiados, 1883524.

offering-lifeline- to-syrian- academics-refugees.

Oliveira, C. R.; Peixoto, J.; Góis, P. (2017). A nova crise dos refugiados na Europa: o modelo de repulsão-atração revisitado e os desafios para as políticas migratórias. $R$. bras. 
Est. Pop., Belo Horizonte, v.34, n.1, p.73-98, jan./abr. DOI http://dx.doi.org/10.20947/S0102-3098a0016.

Pachioni, Miguel (2017). ACNUR. Proyecto de ley que exenta a refugiados de impuestos para la revalidación de diplomas es aprobado en São Paulo. $21 \mathrm{de} \mathrm{dez} \mathrm{de} \mathrm{2017.} \mathrm{[Acesso}$ 13 de janeiro de 2018]. Disponível em: http://www.acnur.org/noticias/noticia/proyecto-deley-que-exenta-a-refugiados-de-impuestos-para-la-revalidacion-de-diplomas-es-aprobadoen-sao-paulo/.

Pastore, José (2015). Educação e trabalho de refugiados. Estadão. http://economia.estadao.com.br/noticias/geral,educacao-e-trabalho-de-refugiados-imp, 1804723.

Pells, R. (2017) London university offers free course just for refugees and asylum seekers. The Independent. http://www.independent.co.uk/news/education/education-news/ university-east-london-free-course-refugees-asylum-seekers-only-erasmus-programmeeu-funding-a7595206.html.

Pujol-Mazzini, Anna. (2016). A student guide to campaigning for refugees. The Guardian. https://www.theguardian.com/education/2016/mar/29/a-student-guide-to-campaigningfor-refugees.

Rossetto, R. (2016). Refugiado tem emprego; falta validar diploma. Estadão. http://saopaulo.estadao.com.br/noticias/geral,refugiado-tem-emprego-falta-validardiploma, 10000026282.

Shabi, Rachel. (2015). The UK universities offering a lifeline to Syrian academics.

Strauss, Valerie. (2017). Mass. college creates 'refugee scholarship' for a student affected by Trump's travel ban. The Washington Post. https://www.washingtonpost.com/news/answer-sheet/wp/2017/02/02/mass-collegecreates-refugee-scholarship-for-a-student-affected-by-trumps-travelban/?utm_term=.a52889b4667d.

Svrluga, Susan. (2017). 'A stunning violation of our deepest American values': Universities respond to Trump's immigration order. The Washigton Post. https://www.washingtonpost.com/news/grade-point/wp/2017/01/30/disruption-anddisorientation-universities-respond-to-trumps-immigrationorder/?utm_term=.9d84607fcb73.

Svrluga, Susan. (2017). 'The U.S. continues to welcome the most talented': Universities respond to Supreme Court action on travel ban. The Washington Post. https://www.washingtonpost.com/news/grade-point/wp/2017/06/26/the-united-statescontinues-to-welcome-the-most-talented-individuals-universities-respond-to-supremecourt-action-on-travel-ban/?utm_term=.457880ec0ab4.

Svrluga, Susan. (2017). Universities respond to new executive order on immigration with concern. The Washington Post. https://www.washingtonpost.com/news/gradepoint/wp/2017/03/06/universities-respond-to-new-executive-order-on-immigration-withconcern/?utm_term=.41d575dc9a1e. 
Tharoor, Ishaan. (2016). Syrian asylum seekers are 'well educated,' Austrian survey finds. The Washington Post. https://www.washingtonpost.com/news/worldviews/ wp/2016/01/12/syrian-asylum-seekers-are-well-educated-austrian-surve finds/?utm_term=.8622f5e98eb8.

Toledo, Luiz Fernando. (2017). Cresce $\mathrm{n}^{\mathbf{0}}$ de universidades brasileiras que acolhem refugiados. Estadão. http://educacao.estadao.com.br/noticias/geral,cresce-n-deuniversidades-brasileiras-que-acolhem-refugiados,70001984155

UNHCR (2017). Left Behind: Refugee Education in Crisis. Sept 2017.

UNHCR, THE UN REFUGE AGENCY (2016). Global Trends. Access: 20/10/17. Available on: http://www.unhcr.org/5943e8a34.

Vieira, M. T. B. P.; Menezes, F. L.; Silva, B. H. (2017). The strength of education in the integration of refugees in Brazil: Russian children in the city of Santos (1958-1968). Rev. Diálogo Educ., Curitiba, v. 17, n. 51, p. 41-59, jan./mar. 2017.

Yohannes, Mihret and Bhatti, Jabeen. (2015). Migrants get help through German online university. USA Today Published. https://www.usatoday.com/story/news/world/2015 /10/29/migrants-get-help-through-german-online-university/74472260/.

Young-Powell, Abby. (2015). University is one place you're not labelled': refugees who flee war to study. Guardian Students. https://www.theguardian.com/education /2015/dec/17/university-is-one-place-youre-not-labelled-refugees-who-flee-war-to-study.

\section{How to cite this article (APA format):}

Almeida, Elzenir Pereira de Oliveira; Silva, Arthur Oliveira; Pereira, Myllena Maria de Morais; Moreira, Elysyana Barros; Nascimento, Sâmia Israele Braz do; Oliveira, Sâneq Alaf de Freitas; Diógenes, Vivianne Coelho Noronha; Rolim Neto, Modesto Leite. Refugee Access to Higher Education in the World: A Systematic Review (2019). Am. In. Mult. J., October. (7) 4, 127147.

Received: $11 / 25 / 2019$

Accepted: 11/29/2019 